\title{
Adalimumab for maintenance treatment of Crohn's disease: results of the CLASSIC II trial
}

\author{
W J Sandborn, S B Hanquer, P Rutgeerts, R N Fedorak, M Lukas, \\ D G Maclntosh, R Panaccione, D Wolf, J D Kent, B Bittle, J Li, \\ P F Pollack
}

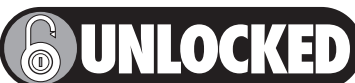

This paper is freely available online under the BMJ Journals unlocked scheme, see http://gut.bmi.com/info/unlocked.dtl
See end of article for authors' affiliations

\section{Correspondence to:} Dr William J Sandborn Mayo Clinic, 200 First Street SW, Rochester, MN 55905, USÁ; sandborn.william@ mayo.edu

Revised version received 25 January 2007 Accepted for publication 29 January 2007 Published online first 13 February 2007
Background: Adalimumab induced clinical remission after four weeks in patients with active Crohn's disease in the CLASSIC I trial.

Objective: To evaluate long term efficacy and safety of adalimumab maintenance therapy in Crohn's disease in a follow-on randomised controlled trial (CLASSIC II).

Methods: In the preceding CLASSIC I trial, 299 patients with moderate to severe Crohn's disease naive to tumour necrosis factor antagonists received induction therapy with adalimumab $40 \mathrm{mg} / 20 \mathrm{mg}, 80 \mathrm{mg} / 40 \mathrm{mg}$, or $160 \mathrm{mg} / 80 \mathrm{mg}$, or placebo, at weeks 0 and 2. In all, 276 patients from CLASSIC I enrolled in CLASSIC II and received open-label adalimumab $40 \mathrm{mg}$ at weeks 0 (week 4 of CLASSIC I) and 2; 55 patients in remission at both weeks 0 and 4 were re-randomised to adalimumab $40 \mathrm{mg}$ every other week, $40 \mathrm{mg}$ weekly, or placebo for 56 weeks. Patients not in remission at both weeks 0 and 4 were enrolled in an open-label arm and received adalimumab $40 \mathrm{mg}$ every other week. With non-response or flare, these patients could have their dosages increased to $40 \mathrm{mg}$ weekly. Patients in the randomised arm with continued non-response or disease flare could switch to open-label adalimumab $40 \mathrm{mg}$ every other week and again to $40 \mathrm{mg}$ weekly. The primary end point was maintenance of remission $(\mathrm{CDAl}<150)$ in randomised patients through week 56 .

Results: Of 55 patients randomised at week 4,79\% who received adalimumab $40 \mathrm{mg}$ every other week and $83 \%$ who received $40 \mathrm{mg}$ weekly were in remission at week $56, v 44 \%$ for placebo ( $<<0.05$ ). In all, 204 patients entered the open-label arm. Of these, $93(46 \%)$ were in clinical remission at week 56 . Adalimumab was generally well-tolerated in all patients.

Conclusions: Adalimumab induced and maintained clinical remission for up to 56 weeks in patients with moderate to severe Crohn's disease naive to anti-TNF treatment. was approved in the United States in February 2007 for the treatment of moderate to severe Crohn's disease. A four-week randomised controlled induction trial, CLASSIC I (Clinical Assessment of Adalimumab Safety and Efficacy Studied as Induction Therapy in Crohn's Disease) demonstrated clinical efficacy at week 4 with loading dose regimens of adalimumab of $80 \mathrm{mg} / 40 \mathrm{mg}$ and $160 \mathrm{mg} / 80 \mathrm{mg}$ given at weeks 0 and 2 for patients with moderately to severely active Crohn's disease who were naive to anti-TNF therapy. ${ }^{26}$ Adalimumab $160 \mathrm{mg} / 80 \mathrm{mg}$ showed the greatest efficacy. ${ }^{26}$

The predefined hypothesis of this study was that sustained adalimumab treatment would maintain long-term clinical remission in a larger proportion of patients with moderate to severe Crohn's disease than would placebo. In CLASSIC II, patients who achieved remission after the four-week induction regimen in CLASSIC I and then maintained remission for an additional four weeks with open-label adalimumab 40 mg every other week were re-randomised to receive blinded adalimumab treatment or placebo for 56 weeks. Patients not in remission at both weeks 0 and 4 of CLASSIC II entered the open-label arm and received adalimumab $40 \mathrm{mg}$ every other week, with the potential to have their dosages increased to $40 \mathrm{mg}$ weekly with non-response or disease flare.

Abbreviations: ANA, antinuclear antibodies; CDAl, clinical disease activity index; CLASSIC: Clinical Assessment of Adalimumab Safety and Efficacy Studied as Induction Therapy in Crohn's Disease trial, ; IBDQ, inflammatory bowel disease questionnaire; LOCF, last observation carried forward rheumatoid arthritis, psoriatic arthritis, psoriasis, and ankylosing spondylitis. ${ }^{18-25}$ Adalimumab is approved by multiple regulatory authorities for the treatment of rheumatoid arthritis, psoriatic arthritis, and ankylosing spondylitis. Adalimumab www.gutjinl.com 


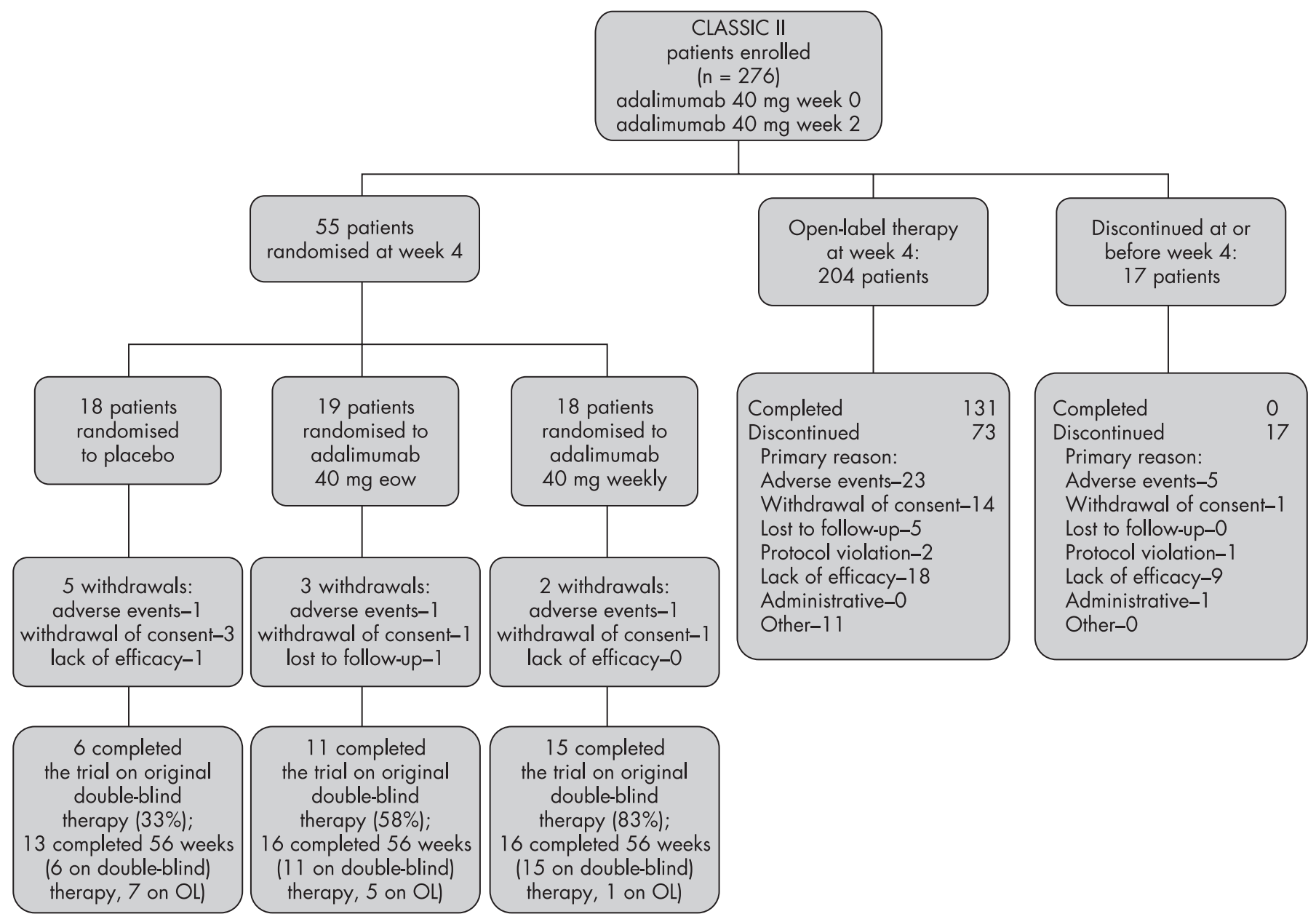

Figure 1 Enrolment and treatment of patients in CLASSIC II. eow, every other week; OL, open-label.

\section{METHODS \\ Patients}

This multicentre, randomised, double-blind, placebo-controlled trial was conducted at 53 centres between 28 August 2002 and 12 January 2005. The protocol was approved by the institutional review board or ethics committee at each centre. All patients provided written informed consent.

All patients who met study entry criteria and successfully completed CLASSIC ${ }^{26}$ were eligible to enrol in CLASSIC II. Female patients of childbearing potential were required to use a highly effective form of birth control, and all patients were required to demonstrate adequate cardiac, renal, and hepatic function as determined by the principal investigator.

\section{Study design}

In the CLASSIC I trial, patients were randomly assigned to receive one of the following subcutaneous induction regimens: placebo at weeks 0 and 2; adalimumab $40 \mathrm{mg}$ at week 0 and $20 \mathrm{mg}$ at week 2; adalimumab $80 \mathrm{mg}$ at week 0 and $40 \mathrm{mg}$ at week 2; or adalimumab $160 \mathrm{mg}$ at week 0 and $80 \mathrm{mg}$ at week 2 . Clinical remission was defined as a Clinical Disease Activity Index (CDAI) score of less than 150 points. ${ }^{27}$ Patients were eligible for enrolment in the randomised cohort of CLASSIC II if they were in clinical remission at both week 0 (week 4 in CLASSIC I) and week 4. At week 4, those in remission were randomly assigned in a $1: 1: 1$ ratio to receive blinded subcutaneous maintenance treatment with adalimumab 40 $\mathrm{mg}$ every other week, adalimumab $40 \mathrm{mg}$ weekly, or placebo from weeks 4 to 55. Patients not in remission at both time points entered the open-label cohort and received $40 \mathrm{mg}$ every other week. All patients were followed to the end of week 56. Assignment to randomised treatment was done centrally. A pharmacist or designee dispensed the study drug according to detailed instructions provided by Abbott Laboratories to each of the study sites.

Dosages employed in this study were selected on the basis of pharmacokinetic data from clinical trials of adalimumab in patients with rheumatoid arthritis. Adalimumab serum concentrations of $4-8 \mu \mathrm{g} / \mathrm{ml}$ achieved with dosages of $40 \mathrm{mg}$ every other week were found to be effective in rheumatoid arthritis. On this basis, a dosage of $40 \mathrm{mg}$ of adalimumab every other week was selected as the target maintenance dosage for efficacy in Crohn's disease. An additional dosage, $40 \mathrm{mg}$ weekly, was also included. This $40 \mathrm{mg}$ weekly dosage was expected to yield adalimumab concentrations slightly greater than $10 \mu \mathrm{g} / \mathrm{ml}$. If randomised patients experienced a flare (defined as both an increase in CDAI to $\geqslant 70$ points above the CLASSIC II week-4 value and a total CDAI score of $>220$ points) or had continued non-response (defined as a decrease in CDAI $\leqslant 70$ points $v$ week-0 value in CLASSIC I), they were permitted to switch to open-label adalimumab $40 \mathrm{mg}$ every other week. These patients were considered failures in the primary efficacy analysis. If patients receiving open-label adalimumab $40 \mathrm{mg}$ every other week flared or had continued non-response, their dosages could be increased to $40 \mathrm{mg}$ weekly. Patients on weekly open-label dosing who continued to flare were discontinued from the study. For the randomised 
Table 1 Baseline characteristics of CLASSIC II patients

\begin{tabular}{|c|c|c|c|c|}
\hline & \multicolumn{3}{|l|}{ Randomised cohort } & \multirow[b]{2}{*}{ OL cohort total } \\
\hline & Placebo & $\begin{array}{l}\text { Adalimumab } 40 \mathrm{mg} \\
\text { every other week }\end{array}$ & $\begin{array}{l}\text { Adalimumab } 40 \mathrm{mg} \\
\text { weekly }\end{array}$ & \\
\hline $\begin{array}{l}\text { Characteristic } \\
\text { Female patients (n (\%)) }\end{array}$ & $\begin{array}{l}n=18 \\
12(67)\end{array}$ & $\mathrm{n}=19$ & $n=18$ & $\mathrm{n}=204 \uparrow \dagger$ \\
\hline $\begin{array}{l}\text { Female patients (n (\%)) } \\
\text { Male patients (n (\%)) }\end{array}$ & $\begin{array}{r}12(67) \\
6(33)\end{array}$ & $\begin{array}{r}12(63) \\
7(37)\end{array}$ & $\begin{array}{l}9(50) \\
9(50)\end{array}$ & $104(51)$ \\
\hline Age (years) (mean (SD)) & $36(13)$ & & $9(50)$ & $100(49)$ \\
\hline Body weight (kg) (mean (SD)) & & $34(12)$ & $38(10)$ & $40(12)$ \\
\hline & $80(13)$ & $69(19)$ & $72(20)$ & 77 (18) \\
\hline & $8.24(8.3)$ & $7.73(6.5)$ & $9.13(9.8)$ & $9.58(8.8)$ \\
\hline Patients who smoked (n (\%)) & $12(67)$ & $13(68)$ & $19(56)$ & $120(59)$ \\
\hline Enterocutaneous or perianal fistula* (n (\%)) & $3(17)$ & $2(11)$ & $0(0)$ & $30(15)$ \\
\hline CDAl score ${ }^{*}$ (mean (SD)) & 107 (62) & $106(33)$ & $88(50)$ & $245(73)$ \\
\hline $\mathrm{IBDQ}^{*}$ (median (range) $) t$ & 191 (138 to 224$)$ & 188 (128 to 213$)$ & $200(138$ to 216$)$ & $149(58$ to 216$)$ \\
\hline \multicolumn{5}{|l|}{ CLASSIC I week-0 CRP $(\mathrm{mg} / \mathrm{dll}) \ddagger$} \\
\hline Mean (SD) & $0.9(1.0)$ & $3.0(3.0)$ & 2.5 (3.3) & $1.6(2.4)$ \\
\hline Median (range) & $0.5(0.0$ to 3.0$)$ & $2.2(0.0$ to 11.3$)$ & $0.7(0.1$ to 9.3$)$ & $0.8(0.0$ to 17.3$)$ \\
\hline \multicolumn{5}{|l|}{$\mathrm{CRP}^{*}(\mathrm{mg} / \mathrm{dl}) \ddagger$} \\
\hline Mean (SD) & $0.2(0.2)$ & $0.8(0.8)$ & $0.6(0.9)$ & $1.3(2.9)$ \\
\hline Median (range) & $0.2(0.0$ to 0.6$)$ & $0.5(0.0$ to 2.7$)$ & $0.2(0.0$ to 3.6$)$ & $0.5(0.0$ to 34.0$)$ \\
\hline \multicolumn{5}{|l|}{ Concomitant drug treatment (n (\%)) } \\
\hline Any corticosteroid & $10(56)$ & $8(47)$ & $9(50)$ & $74(36)$ \\
\hline Systemic corticosteroid§ & $6(33)$ & $4(21)$ & $5(28)$ & $34(17)$ \\
\hline Budesonide & $4(22)$ & $4(21)$ & $4(22)$ & $23(11)$ \\
\hline Any immunosuppressive agent & $3(17)$ & $4(21)$ & $5(28)$ & $67(33)$ \\
\hline Azathioprine & $1(6)$ & $4(21)$ & $2(11)$ & $33(16)$ \\
\hline 6-Mercaptopurine & $1(6)$ & $0(0)$ & $3(17)$ & $25(12)$ \\
\hline Methotrexate & $1(6)$ & $0(0)$ & 0 (0) & $6(3)$ \\
\hline Crohn's-related antibiotics** & $1(6)$ & $0(0)$ & (0) & $25(12)$ \\
\hline 5-Aminosalicylates & $8(44)$ & 14 (74) & $12(67)$ & $110(54)$ \\
\hline
\end{tabular}

*Baseline of CLASSIC II corresponds to week 4 of CLASSIC I.

†Scores for the IBDQ can range from 32 to 224 ; greater scores indicate a better quality of life.

$\ddagger$ High sensitivity cardiology assay for C-reactive protein; normal range is $<0.283 \mathrm{mg} / \mathrm{dl}$.

§Prednisone, prednisolone, methylprednisolone.

-Aminosalicylic acid, mesalazine, and sulfasalazine.

${ }^{* *}$ Metronidazole and ciprofloxacin.

††Excludes 17 patients who discontinued at or before week 4.

CDAl, Clinical Disease Activity Index; CRP, C-reactive protein; IBDQ, Inflammatory Bowel Disease Questionnaire; OL, open-label.

cohort, the patients, study coordinators, and study investigators were all blinded to treatment assignments.

Patients' dosages of all concurrent drugs were required to remain constant, with the exception of corticosteroids. Steroid tapering was mandated for randomised patients at week 8 and was permitted in the open-label cohort for those patients who were responders (that is, who experienced a reduction of $\geqslant 70$ points in CDAI score from week 0 in CLASSIC I). After week 8, daily doses for randomised patients receiving prednisone $>10 \mathrm{mg}$ were reduced by $5 \mathrm{mg}$ weekly until a dosage of 10 $\mathrm{mg}$ /day was reached. Thereafter, dosage was reduced by $2.5 \mathrm{mg}$ weekly to the point of discontinuation. Similarly, budesonide dosage was decreased by $3 \mathrm{mg}$ every week until discontinuation.

Remission was defined as a CDAI $<150$ points. ${ }^{27}$ Response was defined as a reduction of $\geqslant 70$ points (70-point response) or of $\geqslant 100$ points (100-point response) in the CDAI score from week 0 in CLASSIC I.

\section{Efficacy and safety evaluations}

Patients were assessed at weeks 0, 2, 4, 8, 12, 16, 20, 24, 32, 40, 48 , and 56, and CDAI scores were calculated for each visit. CDAI scores range from 0 to 600, with greater scores indicating greater disease activity. The inflammatory bowel disease questionnaire (IBDQ) $)^{28}$ was administered to assess patientreported outcomes at each visit. IBDQ total scores range from 32 to 224 , with greater scores indicating better patient function and quality of life. At each visit, adverse events and concomitant drug treatments were recorded, and samples were collected for standard laboratory evaluations, including antibodies to adalimumab as well as C-reactive protein values.
Safety assessments included vital signs, physical examination, haematology, serum biochemistry, and urinalysis.

\section{Sample size and statistical analysis}

Sample size calculations for the lead-in CLASSIC I study, which called for enrolment of at least 300 patients, have been published. ${ }^{26}$ All patients who completed CLASSIC I were eligible to participate in CLASSIC II, and no additional statistical powering for this follow-on study was conducted. Thus, the analyses described here were exploratory. It was anticipated that approximately $90 \%$ of the patients from CLASSIC I (270 patients) would enrol.

The primary analysis using Pearson's $\chi^{2}$ test evaluated the proportion of patients in remission at week 56 in each arm of the randomised cohort (adalimumb $40 \mathrm{mg}$ every other week, adalimumb $40 \mathrm{mg}$ weekly, and placebo). Those with missing primary end point data at week 56 or those who had moved to open-label dosing were classified in a "no maintenance of remission" category. An initial overall comparison of the three treatment groups (adalimumab $40 \mathrm{mg}$ every other week, adalimumab $40 \mathrm{mg}$ weekly, and placebo) was tested. If significant differences between the three groups were detected, pairwise comparisons of each adalimumab group $v$ the placebo group were conducted.

The Pearson's $\chi^{2}$ test, Fisher's exact test, analysis of covariance (ANCOVA), the Kruskal-Wallis test, and KaplanMeier survival analysis were used as appropriate to provide nominal $\mathrm{p}$ values for secondary end points. Prespecified secondary analyses included the percentages of patients in remission at week 24; 70-point and 100-point clinical responses 


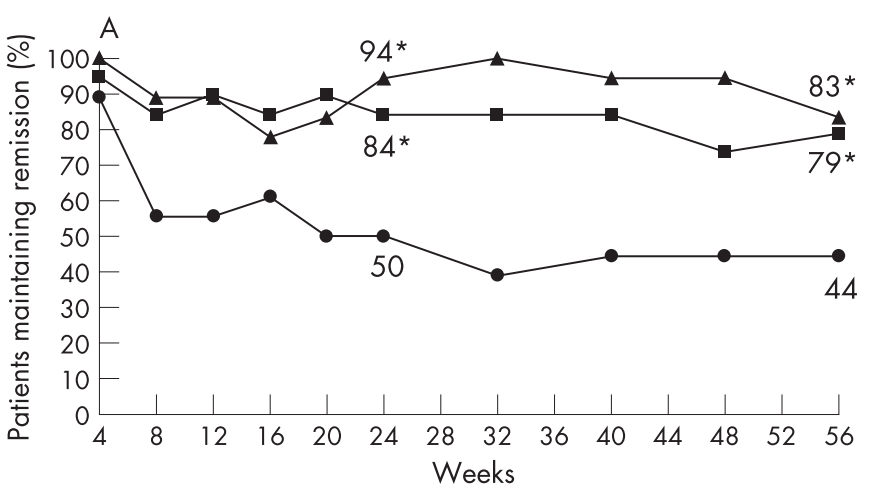

weeks 24 and 56. A subgroup efficacy analysis of patients receiving and not receiving concomitant immunosuppressive agents was also conducted. All secondary analyses were carried out using last observation carried forward (LOCF).

Analyses of the results for patients who received open-label treatment were imputed, and patients who discontinued treatment before week 56 were counted as primary treatment failures.

\section{RESULTS}

\section{Patient characteristics}

In all, 276 patients participated in the study. Fifty-five had achieved remission at weeks 0 and 4 and were randomised (fig 1). In this 55-patient randomised cohort, 18 patients received placebo, 19 received adalimumab $40 \mathrm{mg}$ every other week, and 18 received adalimumab $40 \mathrm{mg}$ weekly. The baseline characteristics of the randomised patients who received placebo were similar to those who received adalimumab (table 1). In the randomised group, five patients $(28 \%)$ withdrew prematurely from the placebo group, $v$ three patients $(16 \%)$ in the adalimumab $40 \mathrm{mg}$ every other week group, and two patients (11\%) in the adalimumab $40 \mathrm{mg}$ weekly group.

In all, 204 patients were ineligible for randomisation and began receiving open-label adalimumab $40 \mathrm{mg}$ every other week at week 4 . In addition, 17 patients discontinued at or before week 4 for the reasons given in fig 1. Baseline characteristics of patients who received open-label adalimumab were similar to those who were randomised (table 1 ). In the open-label group, $36 \%$ of patients discontinued, $11.3 \%$ because of adverse events and $9 \%$ because of lack of efficacy (fig 1 ).

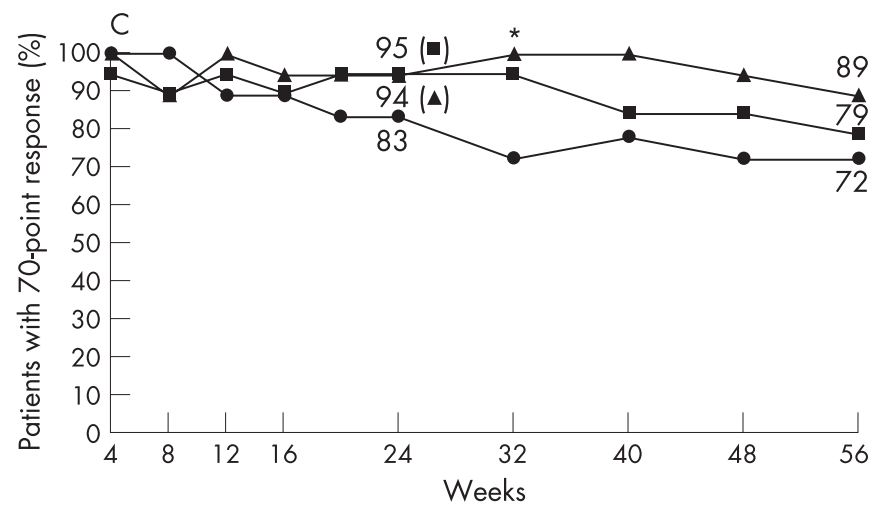

\section{Efficacy}

Randomised patients

All 55 patients were included in the efficacy analyses of the randomised patient group. For the primary analysis at week 56, there was a significant difference in the remission rates between the adalimumab 40-mg every other week group $(15 / 19,79 \%)$, the adalimumab 40-mg weekly group (15/18, $83 \%)$, and the placebo group $(8 / 18,44 \%) \quad(p<0.05$ for each adalimumab group $v$ placebo) (fig $2 \mathrm{~A}$ ). The rates of remission at week 56 were similar for patients receiving concomitant

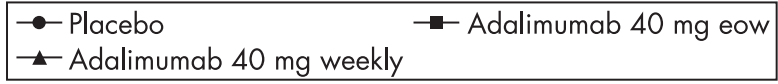

Figure 2 Efficacy of adalimumab as maintenance treatment in Crohn's disease in the randomised cohort. Remission was defined as a decrease in the CDAl score of $<150$ points; 100 -point response was defined as a decrease from CLASSIC I baseline in the CDAI score of $\geqslant 100$ points; and 70-point response was defined as a decrease from CLASSIC I baseline in the CDAl score of $\geqslant 70$ points. Significance was assessed $v$ placebo. (A) The percentage of patients in each adalimumab dose group and the placebo group achieving remission at weeks $4,8,12,16,24,32,40,48$, and 56. ${ }^{*} \mathrm{p}<0.05 v$ placebo, last observation carried forward (LOCF) for intention-to-treat (ITT) population, $n=55$. (B) The percentage of patients in each adalimumab dosage group and the placebo group achieving a 100point response at weeks $4,8,12,16,24,32,40,48$, and 56 . ${ }^{*} \mathrm{p}<0.05$ for adalimumab every other week $v$ placebo at weeks 12 and $20 ; p<0.05$ for adalimumab weekly $v$ placebo at weeks $12,24,32$, and 40 . LOCF for ITT population, $n=55$. (C) The percentage of patients in each adalimumab dosage group and the placebo group achieving a 70-point response at weeks $4,8,12,16,24,32,40,48$, and 56 . ${ }^{*} \mathrm{p}<0.05$ for adalimumab 40 $\mathrm{mg}$ weekly $v$ placebo at week 32 . All data are LOCF for ITT population, $\mathrm{n}=55$. CDAl, Clinical Disease Activity Index; eow, every other week.

at weeks 24 and 56; changes in IBDQ total score from baseline to weeks 24 and 56; and percentages of patients who completely discontinued steroids without loss of remission at

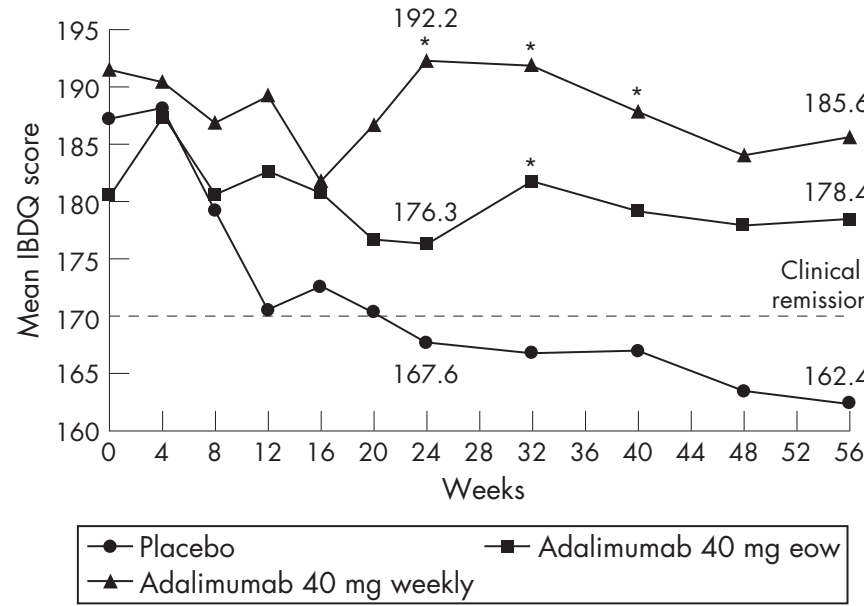

Figure 3 Mean total Inflammatory Bowel Disease Questionnaire (IBDQ) scores by visit: randomised cohort of CLASSIC II. Mean total IBDQ scores in each adalimumab dosage group and the placebo group at weeks $4,8,12$, $16,24,32,40,48$, and 56 . IBDQ values $\geqslant 170$ correlate with clinical remission. All data are last observation carried forward for the intention-totreat population, $n=55$. ${ }^{*} \mathrm{p}<0.05$ for adalimumab every other week $v$ placebo at week $32 ; p<0.005$ for adalimumab $40 \mathrm{mg}$ weekly $v$ placebo at weeks 24,32 , and 40 . eow, every other week. 
immunosuppressants such as azathioprine, 6-mercaptopurine, or methotrexate (adalimumab $40 \mathrm{mg}$ every other week $(4 / 4$, $100 \%)$, adalimumab $40 \mathrm{mg}$ weekly $(4 / 5,80 \%)$, and placebo (1/3, $33 \%)$ ); and patients not receiving concomitant immunosuppressants (adalimumab $40 \mathrm{mg}$ every other week (11/15, 73\%), adalimumab $40 \mathrm{mg}$ weekly (11/13, 85\%), and placebo (7/15, $47 \%))$. Significant differences in remission and 100-point clinical response compared with placebo were demonstrated as early as week 12 in both adalimumab groups (fig 2, panels A and B). The 70-point clinical response rates were numerically greater for the two active treatment groups $v$ placebo (fig 2C).

At week 56, patients in the adalimumab groups had greater mean decreases (improvements) from baseline in CDAI score than patients in the placebo group: 150.8 (95\% confidence interval (CI), -202 to -99.8$)$ and $197.7(-248$ to -147$)$ for the every-other-week and weekly groups, respectively, $v 119.6$ $(-174$ to -65.1 ) for placebo (LOCF, $\mathrm{p}<0.05$ for each adalimumab group $v$ placebo).

In the randomised group, $49 \%$ of patients (27 of 55) were receiving systemic steroids or budesonide at baseline of CLASSIC II. At week 56, 57\% (4/7) of the placebo patients had completely discontinued steroids, compared with $67 \%(4 / 6)$ of the patients in the adalimumab 40 -mg every other week group and $88 \%(7 / 8)$ in the adalimumab 40-mg weekly group (LOCF).

The mean total IBDQ score at the start of CLASSIC II was 186.4. A score $\geqslant 170$ corresponds to clinical remission. A mean total IBDQ score of $\geqslant 170$ was maintained in the groups of randomised patients treated with adalimumab 40-mg every other week or weekly (fig 3), while IBDQ scores declined rapidly in patients receiving placebo. Median C-reactive protein concentrations (mg/dl (range)) at week 24 were 0.5 (0 to 1.2 ), 0.4 (0 to 1.9), and 0.1 ( 0 to 1.6 ) in the placebo, adalimumab 40 mg every other week, and adalimumab 40-mg weekly groups, respectively. At week 56, these C-reactive protein values were 0.4 (0 to 0.9 ), 0.3 (0 to 2.8 ), and 0.3 (0 to 1.2 ), respectively.

\section{Open-label patients}

In all, 204 patients who were not in remission at both week 0 and week 4 entered the open-label cohort. Of these, 131 (64\%) completed 56 weeks of treatment, 71 remained on their initial regimens of adalimumab $40 \mathrm{mg}$ every other week, and 60 had their dosages increased to $40 \mathrm{mg}$ weekly at some point before week 56 . Ninety-three (46\%) of the 204 patients receiving openlabel adalimumab were in remission at week 56, including 56/ 115 (49\%) of those receiving $40 \mathrm{mg}$ every other week and 37/89 $(42 \%)$ of those receiving $40 \mathrm{mg}$ weekly.

One hundred and thirty-two (65\%) of the 204 patients receiving open-label adalimumab achieved a 100-point clinical response at week 56 or last visit, including 73/115 (64\%) with $40 \mathrm{mg}$ every other week and 59/89 (66\%) with 40 mg weekly (LOCF). Moreover, 147/204 patients receiving open-label adalimumab (72\%) achieved a 70-point clinical response at week 56, including 80/115 (70\%) with $40 \mathrm{mg}$ every other week and $67 / 89$ (75\%) with adalimumab $40 \mathrm{mg}$ weekly. In the openlabel cohort, rates of remission and 100-point clinical response (CR-100) at week 56 were similar for patients receiving concomitant immunosuppressants (remission, 48\%; CR-100, $68 \%$ ) and for patients who did not receive concomitant immunosuppressants (remission, 45\%; CR-100, 63\%).

At week 56, patients in the open-label cohort had a mean decrease from baseline in CDAI score of 158.4. In addition, at week $56,58 \%$ of patients receiving steroids at baseline in the open-label cohort $(21 / 36)$ had discontinued them.

\section{Safety}

The most frequently reported treatment-emergent adverse events $(\geqslant 5 \%$ of patients) in the total population of CLASSIC II $(n=276)$ were nasopharyngitis, aggravated Crohn's disease, and sinusitis (table 2). The most frequently reported infectious adverse events were nasopharyngitis, sinusitis not otherwise specified (NOS), upper respiratory tract infection NOS, and influenza. No cases of tuberculosis, coccidioidomycosis, histoplasmosis, aspergillosis, listeria, pneumocystis, or blastomycosis were reported. One placebo patient reported a malignancy (squamous cell carcinoma). No lymphomas occurred during the study, and no patients died. Also, no events of interest for anti-TNF agents-including demyelinating events, lupus-like reactions, and congestive heart failure-were reported. Injection-site reaction NOS and burning were the most commonly reported of injection-site reactions, none of which led to patient withdrawal.

In the randomised cohort, larger percentages of patients randomised to placebo experienced adverse events, serious

Table 2 Summary of safety analyses for CLASSIC II patients to the end of week 56

\begin{tabular}{|c|c|c|c|c|c|}
\hline \multirow[b]{2}{*}{ Variable } & \multicolumn{3}{|c|}{ Randomised cohort } & \multirow{2}{*}{$\begin{array}{l}\text { Patients who received open-label } \\
\text { treatment or discontinued by week } 4 \\
\begin{array}{l}\text { Adalimumab } 40 \mathrm{mg} \text { every other } \\
\text { week }^{*}(\mathrm{n}=221)\end{array}\end{array}$} & \multirow[b]{2}{*}{$\begin{array}{l}\text { Safety set total } \\
(n=276)\end{array}$} \\
\hline & $\begin{array}{l}\text { Placebo } \\
(n=18)\end{array}$ & $\begin{array}{l}\text { Adalimumab } 40 \mathrm{mg} \\
\text { eow }(n=19)\end{array}$ & $\begin{array}{l}\text { Adalimumab } 40 \mathrm{mg} \\
\text { weekly }(\mathrm{n}=18)\end{array}$ & & \\
\hline Adverse events (n (\%)) & $18(100)$ & $15(79)$ & $14(78)$ & $207(94)$ & 254 (92) \\
\hline $\begin{array}{l}\text { Adverse events leading to discontinuation } \\
\text { of study drug ( }(\%))\end{array}$ & $2(11)$ & $1(5)$ & $1(6)$ & $39(18)$ & $43(16)$ \\
\hline \multicolumn{6}{|c|}{ Most frequently reported treatment-emergent adverse events ( $\geqslant 5 \%$ of patients) } \\
\hline Nasopharyngitis & $7(39)$ & $5(26)$ & $2(11)$ & $37(17)$ & $51(19)$ \\
\hline Crohn's disease aggravated & $5(28)$ & $4(21)$ & $2(11)$ & $48(22)$ & $59(21)$ \\
\hline Sinusitis & $1(6)$ & $4(21)$ & $1(6)$ & $20(9)$ & $26(9)$ \\
\hline $\begin{array}{l}\text { Patients with any type of injection-site } \\
\text { reactions }(\mathrm{n}(\%))\end{array}$ & $2(12)$ & $1(5)$ & $0(0)$ & $26(12)$ & $29(12)$ \\
\hline \multicolumn{6}{|c|}{ Patients with treatment-emergent infectious } \\
\hline adverse events (n (\%)) & $15(83)$ & $14(74)$ & $6(33)$ & $127(58)$ & $162(59)$ \\
\hline Malignancies (n (\%)) & $1(5) \dagger$ & $0(0)$ & $0(0)$ & $0(0)$ & $1(0.4)$ \\
\hline Serious adverse events (n (\%)) & $2(11)$ & $1(5)$ & $0(0)$ & 37 (17) & $40(15)$ \\
\hline Serious infections ( $\mathrm{n}(\%)$ ) & $0(0)$ & $0(0)$ & $0(0)$ & $9(4)$ & $0(0)$ \\
\hline
\end{tabular}

*All patients entered the open-label period receiving adalimumab $40 \mathrm{mg}$ every other week. Patients who flared or showed continued non-response could have their dosages increased to $40 \mathrm{mg}$ weekly.

†Squamous cell carcinoma.

eow, every other week. 
adverse events, severe adverse events, and adverse events leading to discontinuation than did patients randomised to either dosage of adalimumab.

Blood concentrations of both adalimumab and antibodies to adalimumab were collected for 269 of the 276 patients in CLASSIC II. Of these 269 , seven $(2.6 \%)$ were determined to have developed antibodies to adalimumab. Of the 269, 84 received concomitant immunosuppressants, none of whom were positive for antibodies to adalimumab. Seven of the 185 patients $(3.8 \%)$ who developed the antibodies did not receive concomitant immunosuppressants. Further, three of the seven patients positive for antibodies to adalimumab (43\%) were in remission at week 24, and two of seven (29\%) were in remission at week 56.

One hundred and eighty-five patients had both baseline and week 56 (or last visit) measurements for antinuclear antibodies (ANA). Of these, 172 were determined to be ANA-negative at baseline, and 33/172 (19\%) were ANA-positive at their final visits. Further, all 33 were positive for antibodies to doublestranded DNA (dsDNA), also at their final visits. Of the 13/185 patients determined to be positive for ANAs at baseline, 4/13 (31\%) were ANA-negative at their final visits, and all of these were negative for antibodies to dsDNA at baseline. Overall, there were no significant findings of clinical laboratory abnormalities, including concentrations of ANAs, and there were no correlations between laboratory findings and clinical efficacy.

\section{DISCUSSION}

The results of this study support the efficacy of adalimumab given subcutaneously at a dosage of $40 \mathrm{mg}$ every other week or weekly versus placebo for inducing and maintaining remission in infliximab-naive Crohn's disease patients with moderate to severe disease activity. Of the randomised patients, those who received adalimumab were approximately 1.5-2.0 times more likely to have maintained remission at 56 weeks. Consistent with these results, randomised patients who received either dosage of adalimumab also had numerically greater rates of 100-point and 70-point responses, and lower disease activity as measured by mean CDAI scores and mean IBDQ total scores, compared with patients who received placebo. However, this study was not powered to detect statistical differences in these measures, and there were relatively small numbers of patients $(<20)$ in each of the three groups of the randomised cohort. Furthermore, the majority of randomised patients in the adalimumab treatment groups and in the open-label cohort who were receiving corticosteroids at baseline of CLASSIC I were without relapse and steroid-free at week 56 . The relatively small number of patients in the randomised cohort receiving steroids at baseline and the open-label nature of the other cohort did not permit statistical comparison. Statistically significant differences in remission and in 100-point clinical response could be observed as early as week 12 (eight weeks after randomisation) $v$ placebo. In addition, while remission rates were similar between randomised patients receiving concomitant immunosuppressants and patients who did not receive concomitant immunosuppressants, the relatively small sample size of the randomised group, as well as the lack of a placebo control in the open-label group, preclude definitive conclusions on the clinical efficacy of concomitant immunosuppression.

Patients who had not achieved remission at both weeks 0 and 4 and entered the open-label cohort represent a more difficult to treat population. Adalimumab therapy resulted in progressive increases in clinical remission at week 56 for $46 \%$ of these patients. Moreover, approximately two-thirds of patients who received adalimumab open-label therapy achieved 100-point improvement in CDAI at week 56, and close to three-quarters achieved a 70-point improvement. Again, response rates were similar between patients who received concomitant immunosuppressants and those who did not.

The results of maintenance treatment with the fully human, $\mathrm{IgG}_{1}$ monoclonal antibody adalimumab in patients with Crohn's disease presented here are broadly similar to those reported for the chimeric $\operatorname{IgG}_{1}$ monoclonal antibody infliximab and for the humanised Fab' antibody fragment conjugated to polyethylene glycol, certolizumab pegol (CDP-870). ${ }^{89} 29$ Infliximab, certolizumab pegol, and adalimumab have each shown efficacy for maintenance of remission in patients with moderately to severely active Crohn's disease who had previously responded to induction treatment with the same agent (drug withdrawal study design). However, while there are one-year maintenance data for adalimumab and infliximab, published data for certolizumab pegol cover six-month analyses only. In contrast, another anti-TNF therapy-the humanised $\mathrm{IgG}_{4}$ monoclonal antibody, CDP-571-failed to show efficacy for induction of remission at 24 to 26 weeks. $^{30}{ }^{31}$ These differences in efficacy between anti-TNF antibodies may at least partially be related to study design. Adalimumab offers a patient advantage over other biological agents for Crohn's disease in that it can be self-administered through subcutaneous injection with either a prefilled syringe or an autoinjection pen.

There was an apparent dosage response across the two randomised adalimumab groups for the end points of remission and the 100-point response at week 56, but no clinically important difference in dosage response was observed between the two maintenance regimens. With either dosage, remission rates were significantly greater than for placebo at most time points after week 12. For induction of remission, results of CLASSIC I suggested that a loading dose of adalimumab 160 $\mathrm{mg}$ at week 0 followed by $80 \mathrm{mg}$ at week 2 (resulting in blood concentrations at week 4 equivalent to $40-\mathrm{mg}$ weekly dosing) is the optimal induction dose. For maintenance of remission, the results of CLASSIC II suggest that both $40 \mathrm{mg}$ every other week and adalimumab weekly are effective. More conclusively, the results from a large maintenance trial comparing adalimumab $40 \mathrm{mg}$ every other week, adalimumab $40 \mathrm{mg}$ weekly, and placebo (the CHARM study) ${ }^{32}$ showed that adalimumab every other week and adalimumab weekly are equally effective in maintaining remission in patients with Crohn's disease.

Maintenance treatment with adalimumab was generally well-tolerated. The rates of serious adverse events were low in patients treated with adalimumab and were similar to placebo. No patients developed serious infectious adverse events, opportunistic infections, tuberculosis, lupus, demyelinating neurological diseases, or lymphoma; and no patients died.

The percentage of patients developing antibodies to the human antibody adalimumab was low $(7 / 269,2.6 \%)$. It should be acknowledged that this small study lacked adequate statistical power to estimate accurately how often antibodies developed to adalimumab compared with placebo, or to explore whether concomitant immunosuppression with azathioprine, 6-mercaptopurine, or methotrexate was protective. However, the results for the total number of patients exposed to adalimumab show that the immunogenicity of adalimumab in patients with Crohn's disease is modest. In patients with rheumatoid arthritis, the rate of formation of antibodies to adalimumab was $5 \%$ ( $1 \%$ for patients receiving concomitant treatment with methotrexate and $12 \%$ for patients receiving adalimumab monotherapy). ${ }^{33}$ The rate of ANA formation observed in CLASSIC II was consistent with what has been observed in controlled and open-label trials of adalimumab in rheumatoid arthritis (data on file and ${ }^{33}$ ) As noted, there were 
no significant findings of clinical laboratory abnormalities, and there were no correlations between laboratory findings and clinical efficacy.

\section{Conclusions}

Subcutaneous administration of adalimumab resulted in maintenance of remission and response, potential steroid sparing effects, and improved quality of life over one year in infliximab-naive Crohn's disease patients with moderate to severe disease activity compared with placebo. Both 40-mg every other week and 40-mg weekly dosages were effective. In this trial, adalimumab was generally well-tolerated. Adalimumab represents an important new therapeutic option for the treatment of Crohn's disease.

\section{ACKNOWLEDGEMENTS}

We thank Kathleen Lomax, MD, of Abbott Laboratories for her input and feedback on the development and revision of this manuscript; Jianhua Zhong PhD, also of Abbott, for his assistance with data acquisition and management; and Michael A Nissen, ELS, Abbott, for his editorial assistance in the development and revision of this paper.

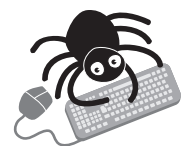

Competing Interests: Declared (the declaration can be viewed on the Gut website at http://www.gutinl.com/ supplemental).

\section{Authors' affiliations}

W J Sandborn, Mayo Clinic, Rochester, MN, USA

S B Hanauer, University of Chicago, Chicago, IL, USA

P Rutgeerts, Universitaire Ziekenhuizen Leuven, UZ Gasthuisberg, Leuven, Belgium

R N Fedorak, University of Alberta, Edmonton, Alberta, Canada M Lukas, Charles University, Prague, Czech Republic

D G MacIntosh, Dalhousie University, Halifax, Nova Scotia, Canada

R Panaccione, University of Calgary, Calgary, Alberta, Canada

D Wolf, Atlanta Gastroenterology Associates, Atlanta, GA, USA

J D Kent, Abbott Laboratories, Abbott Park, Illinois, USA

B Bittle, J Li, P F Pollack, Abbott Laboratories, Parsippany, New Jersey, USA

Funding: This study was funded by a research grant from Abbott Laboratories, Abbott Park, Illinois, USA. It was designed by two of the investigators who are authors of this manuscript (WJS, SBH), as well as Abbott Laboratories staff members. Selected investigators and Abbott staff members, including those who designed the study, analysed, and interpreted the data, wrote this manuscript, and agreed to submit this manuscript for publication. All authors, including the principal investigator (WJS), approved the content of the manuscript prior to submission.

\section{REFERENCES}

1 Romagnani S. Th1/Th2 cells. Inflamm Bowel Dis 1999;5:285-94

2 Murch SH, Lamkin VA, Savage MO, et al. Serum concentrations of tumour necrosis factor alpha in childhood chronic inflammatory bowel disease. Gut 1991;32:913-17.

3 Braegger CP, Nicholls S, Murch SH, et al. Tumour necrosis factor alpha in stool as a marker of intestinal inflammation. Lancet 1992;339:89-91.

4 Murch SH, Braegger CP, Walker-Smith JA, et al. Location of tumour necrosis factor alpha by immunohistochemistry in chronic inflammatory bowel disease. Gut 1993;34:1705-9.

5 Van Deventer SJ. Tumour necrosis factor and Crohn's disease. Gut 1997;40:443-8.

6 Papadakis KA, Targan SR. Tumor necrosis factor: biology and therapeutic inhibitors. Gastroenterology 2000;1 19:1148-57.

7 Targan SR, Hanauer SB, van Deventer SJ, et al. A short-term study of chimeric monoclonal antibody CA2 to tumor necrosis factor alpha for Crohn's disease. Crohn's Disease cA2 Study Group. N Engl J Med 1997;337:1029-35.

8 Rutgeerts P, D'Haens G, Targan S, et al. Efficacy and safety of retreatment with anti-tumor necrosis factor antibody (infliximab) to maintain remission in Crohn's disease. Gastroenterology 1999;1 17:761-9.

9 Hanaver SB, Feagan BG, Lichtenstein GR, et al. Maintenance infliximab for Crohn's disease: the ACCENT I randomised trial. Lancet 2002;359:1541-9.

10 DH, Rutgeerts P, Targan S, et al. Infliximab for the treatment of fistulas in patients with Crohn's disease. N Engl J Med 1999;340:1398-405.
11 BE, Anderson FH, Bernstein CN, et al. Infliximab maintenance therapy for fistulizing Crohn's disease. N Engl J Med 2004;350:876-85.

12 Baert F, Noman M, Vermeire S, et al. Influence of immunogenicity on the long term efficacy of infliximab in Crohn's disease. N Engl J Med 2003;348:601-8.

13 Farrell RJ, Alsahli M, Jeen YT, et al. Intravenous hydrocortisone premedication reduces antibodies to infliximab in Crohn's disease: a randomized controlled trial. Gastroenterology 2003;124:917-24.

14 Hanauer SB, Wagner CL, Bala M, et al. Incidence and importance of antibody responses to infliximab after maintenance or episodic treatment in Crohn's disease. Clin Gastroenterol Hepatol 2004;2:542-53.

15 Cheifetz A, Smedley M, Martin S, et al. The incidence and management of infusion reactions to infliximab: a large center experience. Am J Gastroenerol 2003:98:1315-24.

16 Hanauer S, Rutgeerts P, Targan S, et al. Delayed hypersensitivity to infliximab (Remicade) re-infusion after a 2-4 year interval without treatment [abstract]. Gastroenterology 1999;116:A731.

17 Breedveld FC. Therapeutic monoclonal antibodies. Lancet 2000;355:735-40.

18 den Broeder A, van de Putte L, Rau R, et al. A single dose, placebo controlled study of the fully human anti-tumor necrosis factor-alpha antibody adalimumab (D2E7) in patients with rheumatoid arthritis. J Rheumatol 2002;29:2288-98.

19 van de Putte LB, Rau R, Breedveld FC, et al. Efficacy and safety of the fully human anti-tumour necrosis factor alpha monoclonal antibody adalimumab (D2E7) in DMARD refractory patients with rheumatoid arthritis: a 12 week, phase II study. Ann Rheum Dis 2003:62:1168-77.

20 Weinblatt ME, Keystone EC, Furst DE, et al. Adalimumab, a fully human antitumor necrosis factor alpha monoclonal antibody, for the treatment of rheumatoid arthritis in patients taking concomitant methotrexate: the ARMADA trial. Arthritis Rheum 2003:48:35-45.

21 Weisman MH, Moreland LW, Furst DE, et al. Efficacy, pharmacokinetic, and safety assessment of adalimumab, a fully human anti-tumor necrosis factor-alpha monoclonal antibody, in adults with rheumatoid arthritis receiving concomitant methotrexate: a pilot study. Clin Ther 2003;25:1700-21.

22 Furst DE, Schiff MH, Fleischmann RM, et al. Adalimumab, a fully human anti tumor necrosis factor-alpha monoclonal antibody, and concomitant standard antirheumatic therapy for the treatment of rheumatoid arthritis: results of STAR (Safety Trial of Adalimumab in Rheumatoid Arthritis). J Rheumatol 2003:30:2563-71

23 van de Putte LB, Atkins C, Malaise M, et al. Efficacy and safety of adalimumab as monotherapy in patients with rheumatoid arthritis for whom previous disease modifying antirheumatic drug treatment has failed. Ann Rheum Dis 2004:63:508-16.

24 Keystone EC, Kavanaugh AF, Sharp JT, et al. Radiographic, clinical, and functional outcomes of treatment with adalimumab (a human anti-tumor necrosis factor monoclonal antibody) in patients with active rheumatoid arthritis receiving concomitant methotrexate therapy: a randomized, placebo-controlled, 52-week trial. Arthritis Rheum, 2004;50:1400-11.

25 Rau R, Simianer S, van Riel PL, et al. Rapid alleviation of signs and symptoms of rheumatoid arthritis with intravenous or subcutaneous administration of adalimumab in combination with methotrexate. Scand J Rheumatol 2004;33:145-53

26 Hanauer SB, Sandborn WJ, Rutgeerts $P$, et al. Human anti-tumor necrosis factor monoclonal antibody (adalimumab) in Crohn's disease: the CLASSIC I trial. Gastroenterology 2006;130:323-33.

27 Best WR, Becktel JM, Singleton JW, et al. Development of a Crohn's disease activity index. National Cooperative Crohn's Disease Study. Gastroenterology 1976;70:439-44

28 Irvine EJ, Feagan B, Rochon J, et al. Quality of life: a valid and reliable measure of therapeutic efficacy in the treatment of inflammatory bowel disease. Canadian Crohn's Relapse Prevention Trial Study Group. Gastroenterology 1994; 106:287-96.

29 Schreiber S, Khaliq-Kareemi M, Lawrance I, et al. Certolizumab pegol, a humanised anti-TNF pegylated FAb' fragment, is safe and effective in the maintenance of response and remission following induction in active Crohn's disease: a phase III study (Precise). Gut 2005;54(suppl VII):A82.

30 Sandborn WJ, Feagan BG, Hanauer SB, et al. An engineered human antibody to TNF (CDP571) for active Crohn's disease: a randomized double-blind placebocontrolled trial. Gastroenterology 2001;120:1330-8.

31 Sandborn WJ, Feagan BG, Radford-Smith G, et al. CDP571, a humanised monoclonal antibody to tumour necrosis factor alpha, for moderate to severe Crohn's disease: a randomised, double-blind, placebo-controlled trial. Gut 2004;53:1485-93.

32 Colombel J, Sandborn WJ, Rutgeerts $\mathrm{P}$, et al. Adalimumab for maintenance of clinical response and remission in patients with Crohn's disease: the CHARM Trial. Gastroenterology 2007;132:52-65.

33 Abbott Laboratories. Prescribing information for HUMIRA ${ }^{\circledR}$ (adalimumab). Chicago: Abbott Laboratories, February 2007.

\section{APPENDIX}

The following were investigators in the CLASSIC II study group:

\section{Belgium}

Paul Rutgeerts, Universitaire Ziekenhuizen Gasthuisberg, Leuven

\section{Canada}

Jeffrey Baker, St Michael's Hospital, Toronto, Ontario

Robert Bailey, Alberta, Canada 
Michael Boivin, CHUM-St-Luc, Montreal, Quebec

Robert Enns, St Paul's Hospital, University of British Columbia, Vancouver, British Columbia

Richard Fedorak, Gastrointestinal and Liver Disease Research Group, Edmonton, Alberta

Donald MacIntosh, University of Halifax, Halifax, Nova Scotia Remo Panaccione, University of Calgary, Calgary, Alberta Pierre Pare, CHAUQ Hospital St Sacrement, Foy, Quebec Denis Petrunia, Odyssey Research Services, Victoria, British Columbia

Allan Hillary Steinhart, Mt Sinai Hospital, Toronto, Ontario Gary Wild, Montreal General Hospital, Montreal, Canada

\section{Czech Republic}

Petr Dite, Fakultni Nemocnince Brno-Bohunice, Prague

Radan Kiel, Fakultni Nemocnice MOTOL, Prague

Milan Lukas, Vseobecna Fakultni Nemocnice, Prague

Miroslav Zavoral, Ustredni Vojenska Nemocnice, Prague

\section{Netherlands}

Daniel Hommes, Afd Gastro-enterologie en Hepatologie, AMC Pharmacy, Amsterdam

P Stokkers, Afd Gastro-enterologie en Hepatologie, AMC Pharmacy, Amsterdam

\section{Poland}

Wlodzimierz Bojulko, Oddzial Gastroenterologiczno Internistyczny WSZ W, Szczecin

Eugeniusz Butruk, Klinika Gastroenteroogii CMKP, Warsaw Krzysztof Linke, Katedra i Klinika Gastroenterologii, Pozna Andrzej Nowak, Medical University of Silesia, Katowice Leszek Paradowki, Katedra i Klinika Gastroenterologii, Pozna

\section{USA}

Luis Balart, Louisiana State University Medical School, New Orleans, Louisiana

Peter Banks, Brigham and Women's Hospital, Boston, Massachusetts

Charles Barish, Wake Research Associates, Raleigh, North Carolina

David Binion, Medical College of Wisconsin, Milwaukee, Wisconsin

Charles Birbara, Clinical Pharmacology Study Group, Worcester, Massachusetts

Gregory Bonner, Cleveland Clinic Florida, Weston, Florida William Bray, Digestive Health Specialists, Winston-Salem, North Carolina

William Chey, Rochester Institute for Digestive Disease and Sciences, Rochester, New York

Kiron Das, UMDNJ-Robert Wood Johnson Medical School, New Brunswick, New Jersey

James Doyle, Inland Empire Gastroenterology, Spokane, Washington

Michael Epstein, Digestive Disorders Associates, Annapolis, Maryland

David Eskreis, NY Center for Clinical Research, Lake Success, New York

Fred Fowler, Carolina Research Associates, Charolotte, North Carolina

Stuart Frank, Disease of the Digestive System, Chattanooga, Tennessee
Bradley Freilich, Gastroenterology and Hepatology, Kansas City, Missouri

Daniel Geenen, Wisconsin Center for Advanced Research, Milwaukee, Wisconsin

Stanley Goldberg, Gastroenterology Associates of the East Bay, Berkeley, California

Glen Gordon, Center for Digestive and Liver Diseases, Mexico, Missouri

Stephen Hanauer, University of Chicago, Chicago, Illinois

John Hanson, Charlotte Gastroenterology and Hepatology, Charlotte, North Carolina

Kim Isaacs, Division of Digestive Diseases and Nutrition, Chapel Hill, North Carolina

R Bruce Johnson, Sharp Rees-Stealy Medical Group, San Diego, California

Seymour Katz, Long Island Clinical Research Associates, Great Neck, New York

Alan Kivitz, Altoona Center for Clinical Research, Duncansville, Pennsylvania

Burton Korelitz, New York, New York

Lloyd Mayer, New York, New York

Philip Miner, Oklahoma Foundation for Digestive Research, Oklahoma City, Oklahoma

Pegter Molloy, Pittsburgh, Pennsylvania

Mark Murphy, Southeastern Digestive and Liver Disease Institute, Savannah, Georgia

Daniel Pambianco, Charlottesville Medical Research, Charlottesville, Virginia

Daniel Present, Mount Sinai School of Medicine IBD Research Center, New York

Michael Priebe, Tacoma Digestive Disease Center, Tacoma, Washington

Ronald Pruitt, Nashville Medical Research Institute, Nashville, Tennessee

Alan Safdi, Consultants for Clinical Research, Cincinnati, Ohio William Sandborn, Mayo Clinic, Rochester, Minnesota

Bruce Sands, MCH Digestive Helth Center, Boston, Massachusetts

Ellen Scherl, Inflammatory Bowel Disease Center, New York

Jerrold Lloyd Schwartz, Northwest Gastroenterologists, Arlington Heights, Illinois

Stephen Robert Severance, Long Beach Gastroenterology Associates, Long Beach, California

Ira Shafran, Shafran Gastroenterology Center, Winter Park, Florida

David Silvers, Drug Research Services, Metairie, Louisiana

William Snape, CPMC Clinical Research, San Francisco, California

Stephan Targan, Cedars-Sinai Medical Center, Los Angeles, California

Harvey Tatum, Research Solutions, Tulsa, Oklahoma

Emil Valle, Digestive Disorders Associates, Annapolis, Maryland

Gary Varilek, Gastroenterology Specialties, Lincoln, Nebraska Robert Wohlman, Northwest Gastroenterology, Bellevue, Washington

Douglas Wolf, Atlanta Gastroenterology Associates, Atlanta, Georgia

Strick Woods, Gastroenterology Associates of Fairfield County, Bridgeport, Connecticut

Bradley Zins, Deaconess Billings Clinic Research Division, Billings, Montana 